\title{
Role of moxifloxacin-dexamethasone in cardiac histomorphometric findings among Wistar rats from infected mothers ${ }^{1}$
}

Gustavo Ithamar Souto Maior', Guilherme Veras Mascena", Valéria Wanderley Pinto Brandão Marquis'"', Carlos Alberto Figueiredo Filho'"', Alexandre Rolim da Paz'v, Líbia Cristina Rocha Vilela Mourav, Carlos Teixeira Brandt ${ }^{\mathrm{V}}$

'Fellow PhD degree, Postgraduate Program in Tropical Medicine, Health Sciences Center, Universidade Federal de Pernambuco (UFPE), Recife-PE, Brazil. Acquisition and interpretation of data, manuscript writing.

"Fellow PhD degree, Postgraduate Program in Surgery, Health Sciences Center, UFPE, Recife-PE, Brazil. Statistical analysis, critical revision.

II'Fellow PhD degree, Postgraduate Program in Tropical Medicine, Health Sciences Center, UFPE, Recife-PE, Brazil. Acquisition of data, critical revision.

IVFellow PhD degree, Postgraduate Program in Pathology, Health Sciences Center, Universidade Estadual de Campinas (UNICAMP), Campinas-SP, Brazil. Acquisition and interpretation of data.

VPhD, Head, Postgraduate Program in Tropical Medicine, Health Sciences Center, UFPE, Recife-PE, Brazil. Interpretation of data, final approval.

${ }^{V I}$ PhD, Head, Postgraduate Program in Surgery, Health Sciences Center, UFPE, Recife-PE, Brazil. Interpretation of data, critical revision.

\section{Abstract}

Purpose: To investigate cardiac changes in young rats, whose mothers underwent autogenic fecal peritonitis, during organogenesis phase and to evaluate the role of intravenous administration of moxifloxacin and dexamethasone in preventing infection-related cardiac changes.

Methods: A prospective histomorphometric study was performed on 29 hearts of Wistar fourmonth old rats. Animals were divided into three groups: Negative Control Group (NCG) included 9 subjects from healthy mothers; Positive Control Group (PCG) included 10 subjects from mothers with fecal peritonitis (intra-abdominal injection of $10 \%$ autogenic fecal suspension in the gestational period) and did not receive any treatment; and Intervention Group (IG), with 10 animals whose infected mothers received moxifloxacin and dexamethasone treatment 24 hours after induction of fecal peritonitis.

Results: Nuclear count was higher in the IG group as compared to PCG $(p=0.0016)$ and in NCG as compared to PCG ( $p=0.0380)$. There was no significant difference in nuclear counts between NCG and IG.

Conclusion: Induced autogenic fecal peritonitis in pregnant Wistar rats determined myocardial changes in young rats that could be avoided by the early administration of intravenous moxifloxacin and dexamethasone.

Key words: Peritonitis. Myocardium. Pregnancy. Dexamethasone. Rats. 


\section{Introduction}

Congenital heart disease is the most common detected anomaly at birth and is associated with high morbidity and mortality in childhood and adolescence ${ }^{1}$. The elucidation of mechanisms underlying cardiac development is crucial not only for the identification of abnormalities during organogenesis but also to adopt strategies of early intervention ${ }^{2}$.

The association of ocular and encephalic congenital anomalies in concepts with maternal bacterial endotoxemia has already been demonstrated in pre-clinical study ${ }^{3}$. Induction of peritonitis in rats on the ninth day of pregnancy, using a $10 \%$ filtered autogenic fecal suspension $(4 \mathrm{ml} / \mathrm{kg})$, was associated with the onset of encephalomalacia and cataract. On the other hand, intraperitoneal (IP) injection of moxifloxacin and dexamethasone $48-72 \mathrm{~h}$ after the induction of maternal infection was effective in preventing these complications ${ }^{4}$. This research, however, neither evaluated the histological repercussions of the maternal infection on the offspring nor the intravenous (IV) route for antimicrobial therapy, which is the most used in clinical practice in cases of peritonitis in pregnant women.

The purpose of this study was to investigate cardiac histomorphometry in fourmonth-old Wistar female rats, whose mothers underwent peritonitis with a $10 \%$ autogenic fecal suspension in the early phase of pregnancy (ninth day), during which maximum cardiac organogenesis takes place, and to evaluate the histological cardiac findings of intravenous administration of a combination of moxifloxacin and dexamethasone 24 hours after induction of maternal abdominal infection.

\section{- Methods}

This was a prospective, longitudinal, analytical and interventional study, performed at the Experimental Research Laboratory of the
Medical School from Campina Grande (FCMCG), Paraíba.

Thirty-two Wistar rats (Rattus Novergicus Albinus Rodentia Mammalia) were included in the study. Three female adult rats (mothers) with approximately three months of age $(300 \mathrm{~g})$, without any disease or injury, and 29 young rats (offspring) with 4 months of age were evaluated and monitored.

The animals were housed and cared in accordance with the "Guide for the Care and Use of Laboratory Animals" and the study was conducted respecting the ethical principles in animal experimentation. The animal ethics committee (CEUA/CESED) approved the study protocol under number 5804122015. Animals were provided by the breeding colony of FCM -CG.

Young rats were divided into three groups: Negative Control Group (NCG; $n=9$ ), offspring of rats without induced peritonitis (healthy controls); Positive Control Group (PCG; $n=10$ ), offspring of rats who underwent to induction of autogenic fecal peritonitis but did not receive any treatment; and the Intervention Group (IG; $\mathrm{n}=10)$, offspring of rats with induced autogenic fecal peritonitis who were treated with the intravenous administration of moxifloxacin $(40 \mathrm{mg} / \mathrm{Kg})$ and dexamethasone $(0.2 \mathrm{mg} / \mathrm{kg}) 24$ hours after maternal infectious insult.

Animals that at the time of induction of peritonitis showed signs of any organic fluid in the peritoneal cavity aspirate, evidence of an inflammatory process in the stool, including pus or blood, or which developed malnutrition, were excluded.

The pregnant rats were kept in polypropylene cages measuring $43 \times 43 \times 20$ $\mathrm{cm}$ at a controlled temperature of $23 \pm 1^{\circ} \mathrm{C}$ and 12-hour light/dark cycles. Access to food and drink was ad libitum, with food consisting of a nutritionally balanced rodent diet.

Body weight, respiratory rate and temperature were monitored in a daily basis 
by the same veterinarian. They were also evaluated for the amount and color of the hair in order to detect early signs of infection. The birth of the puppies took place approximately 21 days after pregnancy. All the others survived and showed good development. After the three-week period of breastfeeding, each of the three mothers was separated from their offspring. The male puppies were separated from the females as well.

In two pregnant Wistar rats, fecal peritonitis was induced with $4 \mathrm{ml} / \mathrm{kg}$ of $10 \%$ autogenous fecal suspension in the abdominal cavity in the left lower quadrant on the 9th day of pregnancy (Figure 1). Fecal suspension was obtained from two grams of feces collected from each rat. This sample was dissolved in 20 $\mathrm{ml}$ of $0.9 \%$ saline solution, homogenized and gauze filtered for removing large particles.

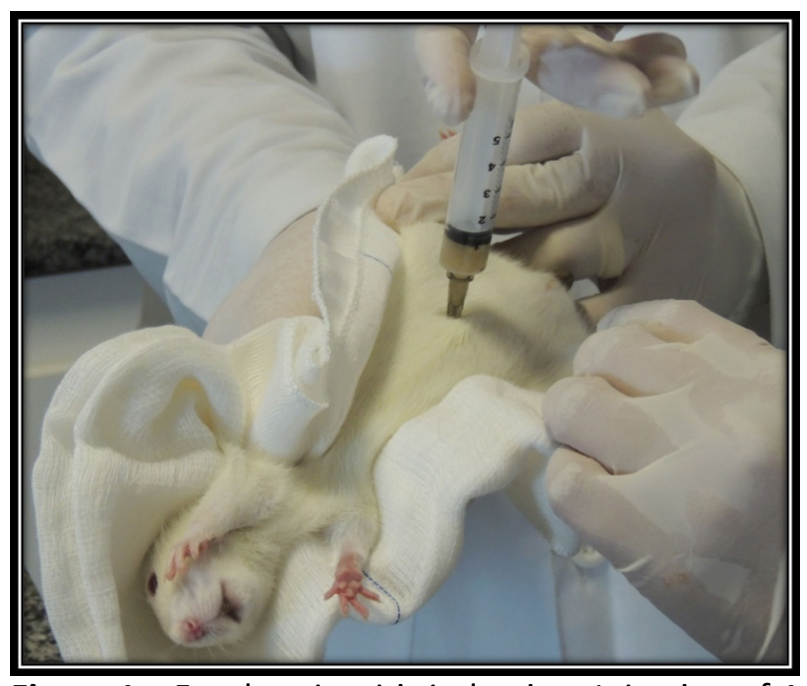

Figure 1 - Fecal peritonitis induction. Injection of 4 $\mathrm{ml} / \mathrm{kg}$ of $10 \%$ autogenous fecal suspension filtered into the left iliac quadrant of the Wistar rat on the 9 th day of pregnancy.

At 4 months of age, young animals $(n=29), 15$ males and 14 females were euthanized with intravenous ketamine hydrochloride, $50 \mathrm{mg} / \mathrm{kg}$, and xylazine, $10 \mathrm{mg} /$ $\mathrm{kg}$. The thoracic cavity was accessed through a midline incision with a 15 cold scalpel blade. The remaining layers of the thoracic wall and the sternum were sectioned with surgical scissors. The heart and great vessels were carefully removed in block (Figure 2), embedded in $10 \%$ formaldehyde and sent for embedment in paraffin and sectioned for the histological slides of approximately $5 \mathrm{~mm}$ thick, from the tip of the heart to the base.

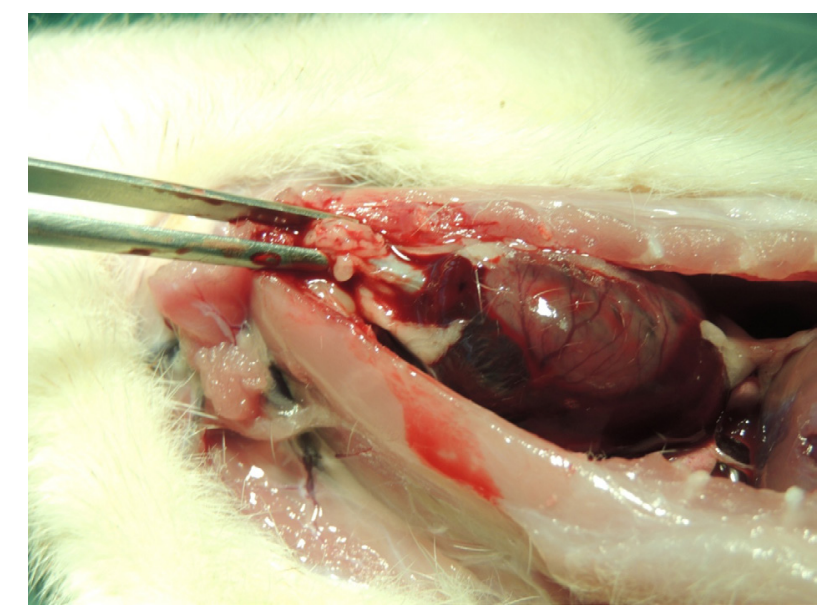

Figure 2 - Heart removal technique. Median thoracotomy by 15 scalpel blade. Isolation and block removal of the heart and great vessels with posterior placement in $10 \%$ formaldehyde.

After washing in running water for one hour, to remove possible formalin precipitations, the material was submitted to a chemical process that allowed adequate and standardized stiffness of the samples for the histological sections.

The chemical process followed an alcoholic sequence for dehydration, in order to render the solutions miscible and avoid tissue retraction. After dehydration, the tissue specimens were immersed in xylene solution, which removes the alcohol. Alcohol is immiscible in molten paraffin, besides being submitted to diaphanization of the tissue. All tissue material was immersed in successive baths of fused paraffin at $60-63^{\circ} \mathrm{C}$ to remove all xylene and to harden the tissue for the histological sections. After chemical tissue processing, all material was sent for inclusion and formation of histological blocks through 
preheated molds.

The immersed material was placed in the mold with the molten paraffin, cooled and then removed from the mold, forming the so-called histological paraffin blocks. Those blocks were cooled at low temperature, promoting further solidification of the paraffin and better grinding of the block during the microtomy. The blocks were stored in a freezer with temperature $-3 \circ \mathrm{C}$ and kept for at least 30 minutes before slicing. The histological slides were identified and serial histological sections were made from the paraffin block, with the purpose of assembling a slide for analysis. The thickness of the obtained cuts was $5 \mu \mathrm{m}$. The cuts already laid on the blade were kept on the stand for about 20 to 30 minutes. Excess paraffin was removed from the "freshly caught" slices by heat in a sterilization oven and dried at about $60-65^{\circ} \mathrm{C}$ for about 30 minutes.

Subsequently, the preparation (submission of chemical substances) of the histological section was made for staining in Hematoxylin and Eosin. The entire process was performed in automatic equipment for staining histological slices, Leica ST5010 model. After staining was completed, the slides analyses were performed and the heart sections were observed under a microscope with $\times 400$ magnification. Representative samples of each section of the left ventricle - free wall - of each mouse, from the respective groups, were randomly selected for analysis.

Histomorphometric analyzes were performed with the aid of a Leica DM 2000 microscope (x40 magnification lens) attached to a digital camera (Leica DFC 425, Leica Microsystems, Wetzlar, Germany) and coupled to a computer equipped with an image analyzer program. In this research, the histomorphometric measurements were performed using the Image J 1.51, Java 1.8.0_101 (64-bit) digital image analysis software. This program is widely used in scientific research involving quantification and analysis of images ${ }^{5-10}$, with programming platform based on the Java language. In a systematic way, all the photomicrographs were processed according to the same algorithm. Initially, the photomicrography was converted to 8-bits. Then in the "processes" tab, image was rendered binary. The data of each image (number, size and nuclear area) were obtained through the "Nucleus Counter" plugin. The "Threshold" command was used to separate the background of the image from the particles of interest. A cut-off point was determined for all particles with an area of less than 100 pixels or greater than 5000 pixels. It was not imposed any restrictions on shape. The cut-off point eliminated artifacts and any coalesced cells.

The results were analyzed using GraphPad Prism (Prism 7 for Mac OS X, Version 7.0c, March 1, 2017 - GraphPad Software, Inc., USA). The quantitative parameters were expressed by their means and standard deviation and represented in box-plot graphs. Each parameter was tested for Gaussian distribution using the Kolmorogov-Smirnov test. For the comparative analysis of the multiple means among the groups that passed the normality test, one-way ANOVA and the Tukey multiple comparisons post-test were used. Comparisons of non-parametric means were performed using the Kruskal-Wallis test. Dunn's post-test was used to identify which groups differed from each other. Values of $p$ $<0.05$ were used to reject the null hypothesis.

\section{Results}

The nuclear count differed among the groups (Kruskal-Wallis - $p=0.0015$ ) and was significantly higher in the NCG when compared to the PCG $(p=0.0380)$. In the IG, a higher nuclear count was also observed when compared to PCG $(p=0.0016)$. There was no significant difference between NCG and IG (Tables 1 and 2, and Figure 3). 
Table 1 - Nuclear counting - Descriptive statistics.

\begin{tabular}{|c|c|c|c|}
\hline & $\begin{array}{l}\text { Without } \\
\text { Peritonitis } \\
\text { (NCG) }\end{array}$ & $\begin{array}{c}\text { Non } \\
\text { Treated } \\
\text { Peritonitis } \\
\text { (PCG) }\end{array}$ & $\begin{array}{l}\text { Intervention } \\
\text { Group } \\
\text { (IG) }\end{array}$ \\
\hline Minimum & 584 & 526 & 429 \\
\hline $\begin{array}{c}25 \% \\
\text { Percentile }\end{array}$ & 769.5 & 594 & 702.3 \\
\hline Median & 833 & 727 & 1103 \\
\hline $\begin{array}{c}75 \% \\
\text { Percentile }\end{array}$ & 1018 & 746 & 1525 \\
\hline Maximum & 1264 & 1110 & 2136 \\
\hline Midium & 894.2 & 700.1 & 1150 \\
\hline $\begin{array}{c}\text { Std. } \\
\text { Deviation }\end{array}$ & 211 & 137.7 & 503.9 \\
\hline $\begin{array}{l}\text { Std. Error } \\
\text { of Mean }\end{array}$ & 58.5 & 31.6 & 112.7 \\
\hline
\end{tabular}

Table 2 - Nuclear counting - Statistical analyses.

\begin{tabular}{lll}
$\begin{array}{l}\text { Dunn's multiple } \\
\text { comparisons test }\end{array}$ & Significant? & $\begin{array}{l}\text { Adjusted } \mathbf{p} \\
\text { value }\end{array}$ \\
\hline NCG vs. PCG & Yes & 0.0380 \\
NCG vs. IG & No & $>0.9999$ \\
PCG vs. IG & Yes & 0.0016 \\
\hline
\end{tabular}

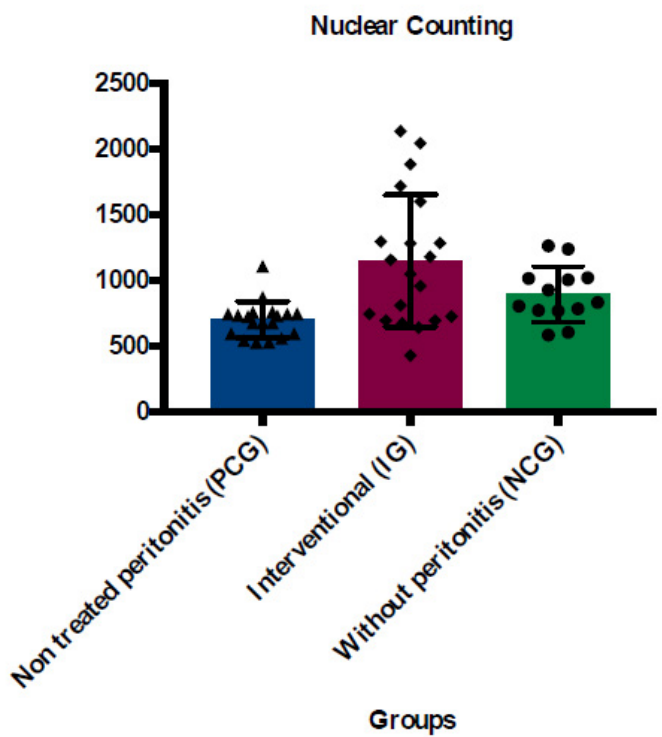

Figure 3 - Nuclear counting per field evaluated in the investigated groups.
The percentage of the photomicrograph area occupied by the nuclei differed among the groups (Kruskal-Wallis - $p=0.0007$ ) and was significantly higher in the NCG when compared to the PCG $(p=0.0448)$ and in the IG group when compared to the PCG ( $p$ $=0.0006)$. There was no significant difference between NCG and IG groups (Tables 3 and 4, Figure 4).

Table 3 - Area of photomicrography (\%) occupied by nuclei - Descriptive statistics.

\begin{tabular}{cccc}
\hline & $\begin{array}{c}\text { Without } \\
\text { Peritonitis } \\
\text { (NCG) }\end{array}$ & $\begin{array}{c}\text { Non } \\
\text { Treated } \\
\text { Peritonitis } \\
\text { (PCG) }\end{array}$ & $\begin{array}{c}\text { Intervention } \\
\text { Group } \\
\text { (IG) }\end{array}$ \\
\hline $\begin{array}{c}\text { Minimum } \\
\text { 25\% }\end{array}$ & 2.4 & 2.6 & 2.0 \\
$\begin{array}{c}\text { Percentile } \\
\text { Median }\end{array}$ & 4.2 & 3.1 & 3.8 \\
$\begin{array}{c}\text { 75\% } \\
\text { Percentile }\end{array}$ & 5.5 & 3.6 & 5.9 \\
$\begin{array}{c}\text { Maximum } \\
\text { Midium }\end{array}$ & 8.7 & 3.9 & 9.8 \\
$\begin{array}{c}\text { Std. } \\
\text { Deviation }\end{array}$ & 1.6 & 0.1 & 12.8 \\
$\begin{array}{c}\text { Std. Error } \\
\text { of Mean }\end{array}$ & 4.5 & 0.2 & 6.9 \\
\hline Kust-Wallis & & 3.7 & 0.8 \\
\hline
\end{tabular}

Kruskal-Wallis test $(p=0.0007)$

Table 4 - Area of photomicrography (\%) occupied by nuclei - Statistical analyses.

\begin{tabular}{cll}
$\begin{array}{c}\text { Dunn's } \\
\text { multiple } \\
\text { comparisons } \\
\text { test }\end{array}$ & Significant? & $\begin{array}{c}\text { Adjusted } p \\
\text { value }\end{array}$ \\
\hline NCG vs. PCG & Yes & 0.0448 \\
NCG vs. IG & No & $>0.9999$ \\
PCG vs. IG & Yes & 0.0006 \\
\hline
\end{tabular}




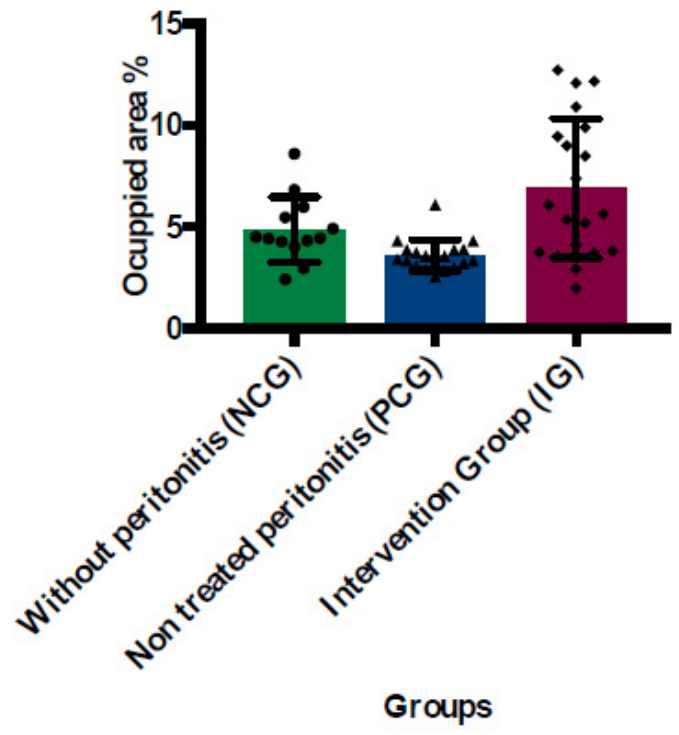

Figure 4 - Area of photomicrography (\%) occupied by nuclei.

The nuclear size differed among the groups (ANOVA - $p=0.0207$ ). This variable was significantly higher in IG when compared to PCG ( $p=0.0170)$. There was no significant difference between NCG and IG groups, nor between NCG and PCG groups (Tables 5 and 6 , Figure 5).

Table 5 - Nuclear size (pixels) - Descriptive statistics.

\begin{tabular}{|c|c|c|c|}
\hline & $\begin{array}{l}\text { Without } \\
\text { Peritonitis } \\
\text { (NCG) }\end{array}$ & $\begin{array}{l}\text { Non } \\
\text { Treated } \\
\text { Peritonitis } \\
\text { (PCG) }\end{array}$ & $\begin{array}{l}\text { Intervention } \\
\text { Group } \\
\text { (IG) }\end{array}$ \\
\hline Minimum & 380584 & 472049 & 485281 \\
\hline $\begin{array}{c}25 \% \\
\text { Percentile }\end{array}$ & 497572 & 509866 & 541215 \\
\hline Median & 577524 & 540007 & 626429 \\
\hline $\begin{array}{c}75 \% \\
\text { Percentile }\end{array}$ & 623857 & 595697 & 678605 \\
\hline Maximum & 719346 & 616406 & 769391 \\
\hline Midium & 570701 & 546566 & 617717 \\
\hline $\begin{array}{c}\text { Std. } \\
\text { Deviation }\end{array}$ & 100882 & 45246 & 85052 \\
\hline $\begin{array}{l}\text { Std. Error } \\
\text { of Mean }\end{array}$ & 27980 & 10380 & 19018 \\
\hline
\end{tabular}

ANOVA $(p=0.0207)$
Table 6 - Nuclear size - Statistical analyses.

\begin{tabular}{ccc}
$\begin{array}{c}\text { Tukey's multiple } \\
\text { comparisons test }\end{array}$ & Significant & $\begin{array}{c}\text { Adjusted } \\
\text { P value }\end{array}$ \\
\hline NCG vs. PCG & No & 0.6665 \\
NCG vs. IG & No & 0.2167 \\
PCG vs. IG & Yes & 0.0170 \\
\hline
\end{tabular}

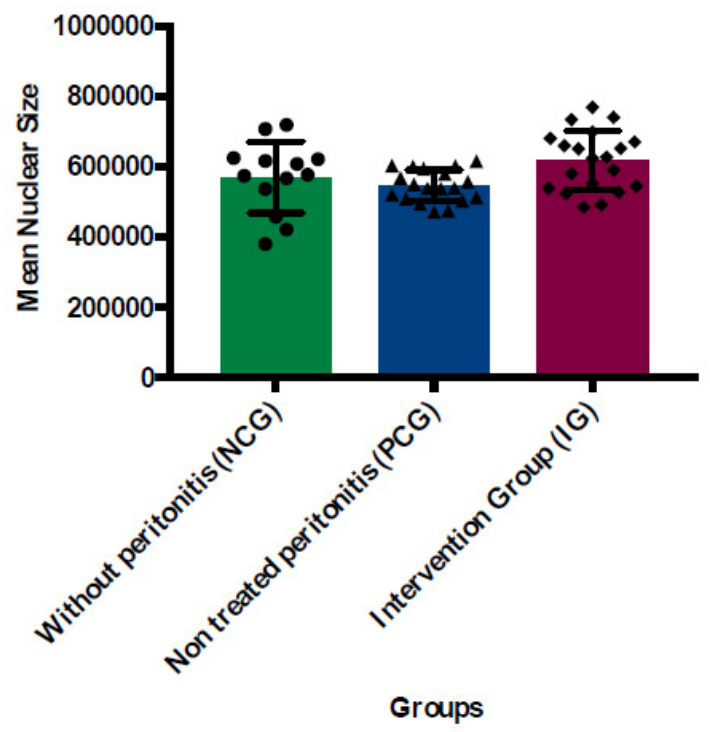

Figure 5 - Nuclear size (pixel).

\section{- Discussion}

Cardiac histological changes in Wistar rats have been demonstrated in infarct models ${ }^{11}$. However, evidence linking experimentally induced maternal peritoneal infection to fetal cardiovascular repercussions is scarce.

In the present study, ImageJ software was used to perform the histomorphometric analysis and to investigate fetal cardiac alterations caused by maternal bacterial endotoxemia in pregnant Wistar rats.

The nuclear count and the percentage of occupied nucleus area was significantly higher in the NCG compared to PCG and PCG than in the IG, pointing to a reduction in nuclear density 
and greater apoptotic activity, as determined by maternal peritonitis. Therefore, the absence of a significant difference in nuclear counts between the IG and NCG groups indicated the efficacy of the treatment (intravenous moxifloxacin and dexamethasone), dose (40 $\mathrm{mg} / \mathrm{kg}$ and $0.2 \mathrm{mg} / \mathrm{kg}$ respectively) used in the $\mathrm{Gl}$, to control the maternal infectious process.

No significant difference was found in nuclear NCG size when compared to PCG or IG. However, the nuclear size in PCG was lower than in IG. It is possible that the greater dispersion of the NCG (amplitude of 117 190) compared to the PCG (amplitude of 144 - 357), compared to a small sample, justifies the absence of significant statistical difference between the groups evidenced by the Tukey multiple comparison test ( $p=0.6665)$.

Fluoroquinolone antibacterial compounds are treatment options of increasing importance for bacterial infections. In recent years, immunomodulatory treatments of infectious diseases have attracted the attention of researchers, increasing their expectations for additional benefits apart from that of the antibiotics. Accumulated knowledge attributes the beneficial effect of dexamethasone to its potential to reduce inflammatory mediators. In vitro studies support the finding that dexamethasone promotes phagocytosis by human monocytes, not only of S. aureus, but of other macromolecules as well, and thereby may contribute to tissue repair after immunemediated tissue damage or infection ${ }^{12}$.

In experimental studies with murine, the age of the animals is as important as the weight to evaluate a therapeutic intervention. The three mother pregnant rats in the present study had similar ages, approximately 12-month old.

In human beings as maternal ages increases, the rates of cesarean section are high, and fetal death and neonatal morbidity and mortality also grow. The incidence and mortality rate due to maternal sepsis have increased in the last decade. In the US, the maternal mortality rate increased from 12 per 100,000 live births in 1990 to 14 per 100,000 live births in $2015^{13,14}$.

Immunosenescence, a decline in the immune system with increasing age is one of the factors that justify the increase in maternal mortality in recent years. The relevance of these data led the United Nations (UN) to determine that reducing maternal mortality by 75 percent in 15 years would be one of the main goals for the millennium. This goal was not achieved by most industrialized countries ${ }^{15}$. Although the results of this research had been obtained in young rats from adult mothers with peritonitis, it is possible that the cardiac alterations found in rats from elderly mothers needs further investigation.

In the face of maternal sepsis, newborns have high rates of adverse events. Infection of the amniotic fluid can occur at any stage of gestation, but it is more frequent near childbirth or in the puerperium. Aerobic and anaerobic germs, gram positive and negative, are the most commonly found flora - mixed flora ${ }^{15}$.

In late neonatal sepsis, changes in heart rate, reduced heart rate variability and decelerations are observed, often up to 12 to 24 hours before the clinical diagnosis of sepsis. The analysis of heart rate variability is usually attributed to a dysfunction of the sinus node cells caused by the release of cytokines and alterations in cellular transduction processes, or changes in the central and autonomic nervous system, with consequent impairment of the feedback control circuit for heart rate variation ${ }^{16}$. However, the reduction in PCG count and nuclear area in comparison to NCG raises the hypothesis that, as evidenced in left ventricular free wall cardiomyocytes in the adult offspring of rats that had induced 
peritonitis in the organogenesis, there may be histomorphometric changes in the cardiac conduction system. In this situation, the sinus node would play an active role in the genesis of arrhythmias. Changes in heart rate variability would be caused directly by involvement of the sinus node by maternal infection.

The association of peritoneal infection in pregnant rats with the appearance of encephalomalacia and ocular alterations (cataract) in their offspring has already been demonstrated $^{3}$. The similarity of the degree of differentiation of the neuronal cells of the brain with the cells of the cardiac conduction system reinforces the suspicion that the cardiac histomorphometric findings of the free wall of the left ventricle, evidenced in this research, can be extended to the cardiac conduction tissue.

The results support a better understanding of the fetal cardiac repercussion caused by the bacterial translocation of the maternal abdominal cavity into the fetal blood circulation. In a scenario of experimental infection, involving the maternal-fetal binomial, this research originally showed that early treatment of maternal peritoneal infection with intravenous corticoid-associated antibiotic may avoid fetal heart changes.

\section{Conclusions}

In pregnant adult rats that underwent to peritonitis with $4 \mathrm{ml} / \mathrm{kg}$ of $10 \%$ autogenous fecal filtrate solution, a statistically significant reduction in nuclear counts and percentage of the area occupied by tissue nuclei was observed from the histomorphometric analysis with the ImageJ software in the young rats. These changes were prevented with early and intravenous administration of moxifloxacin $40 \mathrm{mg} / \mathrm{kg}$ and dexamethasone $0.2 \mathrm{mg} / \mathrm{kg}$. No significant difference was observed in nuclear size when comparing PCG groups with NCG, however, it was observed that the nuclear size in the IG was greater than in the PCG.

\section{References}

1. Khalil A, Suff N, Thilaganathan B, Hurrell A, Cooper D, Carvalho JS. Brain abnormalities and neurodevelopmental delay in congenital heart disease: systematic review and metaanalysis. Ultrasound Obstet Gynecol. 2014;43(1):14-24. doi: 10.1002/uog.12526.

2. Chen $H$, Vanburen V. A provisional gene regulatory atlas for mouse heart development. PLoS One. 2014;9(1):e83364. doi: 10.1371/journal.pone.0083364.

3. Brandt CT, Melo MCSC, Gadelha DNB, Gadelha NNCB, Oliveira TKB, Falcão MPMM. Brain damage and congenital cataract due to autogenously fecal peritonitis in pregnant Wistar rats. Acta Cir Bras. 2014;29(10):6817. PMID: 25318001.

4. Nery D, Gadelha B, Brandt CT. Severe autogenously fecal peritonitis in Wistar rats with permanent bilateral carotid. Response to intraperitoneal moxifloxacin combined with dexamethasone. Acta Cir Bras. 2014;29(2):76-81. PMID: 24604309.

5. Daunoravicius D, Besusparis J, Zurauskas $E$, Laurinaviciene $A$, Bironaite $D$, Pankuweit $S$, Plancoulaine $B$, Herlin P, Bogomolovas J, Grabauskiene V, Laurinavicius A. Quantification of myocardial fibrosis by digital image analysis and interactive stereology. Diagn Pathol. 2014;9:114. PMID: 24912374.

6. Lousinha A, Antunes E, Borrecho G, Oliveira MJ, Brito J, dos Santos JM. Histomorphometric evaluation of the small coronary arteries in rats exposed to industrial noise. Int J Mol Sci. 2015;16(5):10095-104. PMID: 26227715.

7. Rossini KF, Andrea De Oliveira C, Rebelato $\mathrm{J}$, Augusto $\mathrm{M}$, Esquisatto $\mathrm{M}$, Catisti R. Gestacional protein restriction increases cardiac connexin 43 mRNA levels in male adult rat offspring. Arq Bras Cardiol. 2017;109(1):63-70. PMID: 28678925.

8. Grishagin I V. Automatic cell counting with ImageJ. Anal Biochem. 2015;473:63-5. PMID: 25542972.

9. Schneider C, Rasband W, Eliceiri K. NIH Image to Image J: 25 years of image analysis. Nat 
Methods. 2012;7:671-5. PMID: 22930834. 10.Girish V, Vijavalakshmi A. Affordable image analysis using NIH Image/Image J. Indian J Cancer. 2004; 41(1):47. PMID: 15105580.

11.Zaki SM, Abdalla IL, Sadik AO El, Mohamed EA, Kaooh S. Protective role of $\mathrm{N}$-acetylcysteine on isoprenaline-Induced myocardial injury: histological, immunohistochemical and morphometric study. Cardiovasc Toxicol. 2018;18(1):9-23. PMID: 28439707.

12. Skiadas I, Pefanis A, Papalois A, Kyroudi A, Triantafyllidi $H$, Tsaganos $T$, Giamarellou $\mathrm{H}$. Dexamethasone as adjuvant therapy to moxifloxacin attenuates valve destruction in experimental aortic valve endocarditis due to Staphylococcus aureus. Antimicrob Agents Chemother. 2007;51(8):2848-54. PMID: 17562794.
13. Chescheir NC. Enough already! Obstet Gynecol. 2015;125(1):2-4. PMID: 25560096. 14.Creanga AA, Berg CJ, Syverson C, Seed K, Bruce FC, Callaghan WM. Pregnancy-related mortality in the United States, 2006-2010. Obstet Gynecol. 2015;125(1):5-12. PMID: 25560097.

15.Lisonkova S, Potts J, Muraca GM, Razaz N, Sabr Y, Chan S, Kramer MS. Maternal age and severe maternal morbidity : a populationbased retrospective cohort study. PLos Med. 2017;14(5):e1002307. PMID: 28558024.

16.Griffin MP, O'Shea TM, Bissonette EA, Harrell FE, Lake DE, Moorman JR. Abnormal heart rate characteristics preceding neonatal sepsis and sepsis-like illness. Pediatr Res. 2003;53(6):920-6. PMID: 12646726.

\section{Correspondence:}

Carlos Teixeira Brandt

Avenida Senador Argemiro de Figueiredo, 1901

58.411-020 Campina Grande - PB Brasil

Tel.: (55 83)98105-5920

carlosbrandt@bol.com.br

Received: May 10, 2018

Review: July 12, 2018

Accepted: Aug 10, 2018
Conflict of interest: none

Financial source: Faculty of Medical Sciences of Campina Grande

${ }^{1}$ Research performed at Experimental Research Unit, UNIFACISA, Medical Sciences, Faculty of Campina Grande (FCM), Paraiba, Brazil. Part of Master degree thesis, Postgraduate Program in Tropical Medicine, UFPE. Tutor: Prof. Carlos Teixeira Brandt. 